\title{
Disruption of cholesterol homeostasis by plant sterols
}

\author{
Chendong Yang, ${ }^{1}$ Liqing Yu, ${ }^{1}$ Weiping Li, ${ }^{2}$ Fang $\mathrm{Xu},{ }^{3}$ Jonathan C. Cohen, ${ }^{3}$ and Helen H. Hobbs ${ }^{1,4}$ \\ 1Department of Molecular Genetics, McDermott Center for Human Growth and Development, ${ }^{2}$ Department of Cell Biology, \\ ${ }^{3}$ Center for Human Nutrition, and ${ }^{4}$ Howard Hughes Medical Institute at the University of Texas Southwestern Medical Center, Dallas, Texas, USA.
}

\begin{abstract}
The ABC transporters ABCG5 and ABCG8 limit absorption and promote excretion of dietary plant sterols. It is not known why plant sterols are so assiduously excluded from the body. Here we show that accumulation of plant sterols in mice lacking ABCG5 and ABCG8 (G5G8-/- mice) profoundly perturbs cholesterol homeostasis in the adrenal gland. The adrenal glands of the $\mathrm{GSG8}^{-/-}$mice were grossly abnormal in appearance (brown, not white) due to a $91 \%$ reduction in cholesterol content. Despite the very low cholesterol levels, there was no compensatory increase in cholesterol synthesis or in lipoprotein receptor expression. Moreover, levels of ABCA1, which mediates sterol efflux, were increased 10 -fold in the $\mathrm{G5G8}^{-/-}$adrenals. Adrenal cholesterol levels returned to near-normal levels in mice treated with ezetimibe, which blocks phytosterol absorption. To determine which plant sterol(s) caused the metabolic changes, we examined the effects of individual plant sterols on cholesterol metabolism in cultured adrenal cells. Addition of stigmasterol, but not sitosterol, inhibited SREBP-2 processing and reduced cholesterol synthesis. Stigmasterol also activated the liver $X$ receptor in a cellbased reporter assay. These data indicate that selected dietary plant sterols disrupt cholesterol homeostasis by affecting two critical regulatory pathways of lipid metabolism.
\end{abstract}

\section{Introduction}

Cholesterol and plant sterols are structurally similar, but undergo strikingly different metabolic fates in mammals. Plant sterols (including sitosterol, campesterol, and stigmasterol) represent a large proportion of dietary sterols, and yet the concentration of plant sterols in the blood and tissues of normal mammals is uniformly low when compared to the concentration of cholesterol (1). The accumulation of plant sterols is actively prevented by two members of the ABC transporter family, ABCG5 and ABCG8 $(2,3)$.

Both proteins are expressed in the intestine and the liver, where they function as a heterodimer to limit the absorption of dietary sterols and to promote the excretion of sterols from the liver into the bile. Mutations in ABCG5 and ABCG8 cause sitosterolemia, an autosomal recessive disorder in which plasma and tissue levels of plant sterols are increased 30-200 fold $(4,5)$. Patients with sitosterolemia are frequently, but not invariably, hypercholesterolemic. A striking finding of this disorder is the markedly reduced rate of endogenous cholesterol synthesis, even in those patients with normal plasma cholesterol levels (5). The molecular mechanism responsible for the very low rate of cholesterol synthesis in these patients is not known.

ABCG5 and ABCG8 are highly conserved among vertebrate species, and they efficiently exclude plant sterols from animal tissues. The low levels of plant sterols in animals has made it difficult to assess their biological effects. The reason why noncholesterol sterols are selectively eliminated from the body is not known. To

Nonstandard abbreviations used: ACAT, acyl-CoA:cholesterol acyltransferase; FPPS, farnesyl diphosphate synthase; $G 5 G 8^{-/-}$mice, mice lacking ABCG5 and ABCG8; HMGCR, HMG-CoA reductase; HMGCS, HMG-CoA synthase; HSL, hormone-sensitive lipase; LDLR, LDL receptor; LXR, liver X receptor; LXR- $\alpha$, liver X receptor ligand binding site; NCLPPS, newborn calf lipoprotein-poor serum; SR-BI, scavenger receptor class B type I.

Conflict of interest: The authors have declared that no conflict of interest exists.

Citation for this article: J. Clin. Invest. 114:813-822 (2004)

doi:10.1172/JCI200422186. examine the effects of plant sterols on cholesterol homeostasis, we developed mice lacking ABCG5 and ABCG8 (G5G8 $8^{-/-}$mice) (6). These knockout mice have a greater than 30 -fold increase in mean plasma and hepatic levels of plant sterols. The mice appear healthy and fertile and have no gross abnormalities (6). The accumulation of plant sterols is associated with a compensatory decrease in cholesterol levels so that the total sterol content of the plasma and liver are not significantly altered (7).

In addition to playing an important structural role in cell membranes, sterols are also required for synthesis of adrenal and gonadal steroid hormones. Although the adrenal gland can synthesize cholesterol, the major source of cholesterol for steroidogenesis is circulating lipoproteins $(8,9)$. Cholesterol is acquired from circulating HDL by selective uptake via the scavenger receptor class B type I (SR-BI), and from circulating LDL by endocytosis mediated by the LDL receptor (LDLR) $(10,11)$. In mice, HDL is the major source of cholesterol for steroidogenesis in the adrenal gland $(8,9,12)$, whereas in humans most adrenal cholesterol is derived from LDL (13). The levels of SR-BI and LDLR in the adrenal glands increase in response to the pituitary hormone ACTH, which orchestrates the upregulation of many genes involved in the metabolism of cholesterol and its conversion to corticosteroids (14-16). Corticosteroid synthesis is under feedback regulation so that when the levels of corticosteroids rise in the blood, ACTH secretion is inhibited, decreasing steroidogenesis. Administration of dexamethasone, a potent synthetic corticosteroid, dramatically reduces adrenal steroidogenesis. Disruption of cholesterol uptake into adrenal cells in mice, either by depleting circulating HDL (17, 18) or by inactivating SR-BI (19), reduces the cholesterol ester content of the adrenal gland. In both ApoaI ${ }^{-/-}$and Srb1 $1^{-/-}$mice, cholesterol synthesis is increased in the adrenal gland to maintain the concentration of free cholesterol in adrenal cells.

Another source of cholesterol for steroidogenesis is cholesteryl esters stored in cytoplasmic lipid droplets. Unlike in the liver and most other tissues, where only a small fraction of tissue choles- 


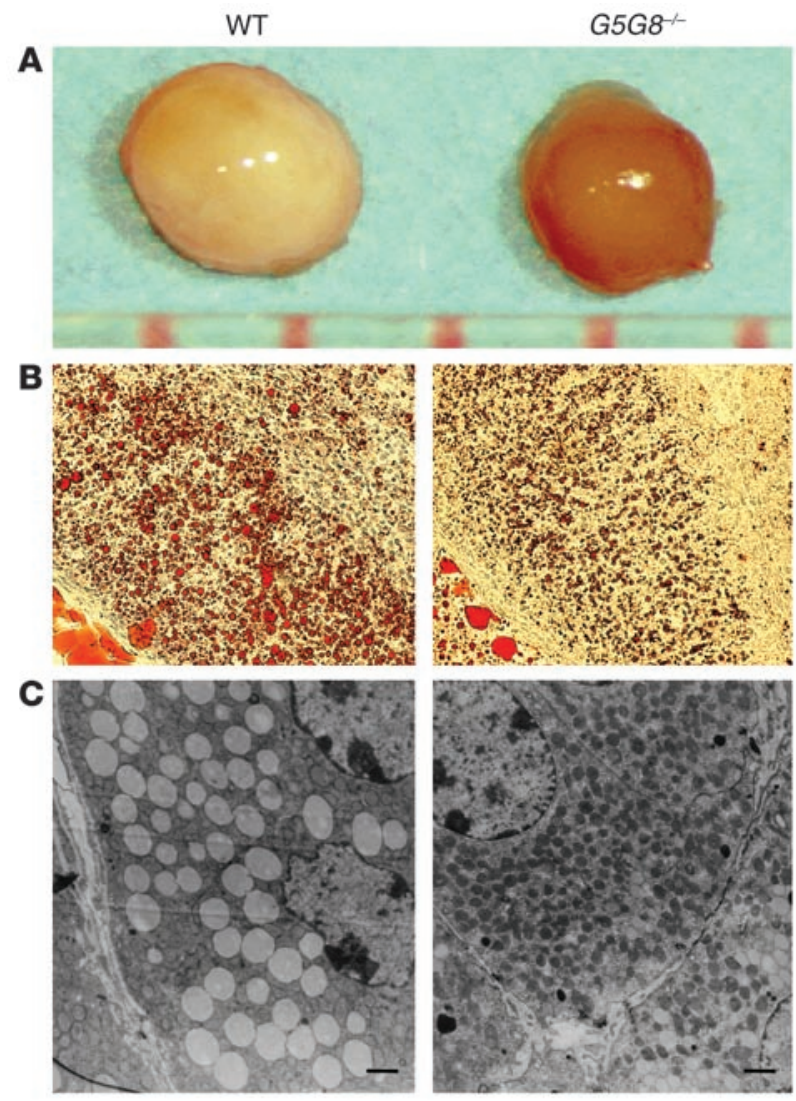

terol is esterified, most cholesterol in the steroidogenic cells of the adrenal gland, testis, and ovary is esterified (20). Mice lacking the form of acyl-CoA:cholesterol acyltransferase (ACAT) expressed in the adrenal glands have lipid-depleted adrenal cells (21). Consequently, the rate of cholesterol synthesis is increased in the adrenal glands of the Acat1 $1^{-/-}$mice.

\section{Results}

Cholesteryl ester depletion in the adrenal gland of $\mathrm{G} 5 \mathrm{G} 8^{-1-}$ mice. The gross appearance of adrenal glands in $\mathrm{G5} \mathrm{G}^{-/-}$mice differed markedly from that of age- and sex-matched wild-type mice. The adrenal glands of wild-type mice were pale pink, whereas those of the G5G8 ${ }^{-/-}$mice were reddish brown (Figure 1A). Staining of adrenal tissue with Oil Red O revealed significantly less lipid accumulation in the adrenal cortex of $G 5 \mathrm{GS}^{-/-}$mice versus wild-type mice (Figure 1B). The lipid droplets in the cytoplasm of the adrenal cells in the zona fasiculata and the zona reticularis of the $\mathrm{G} 5 \mathrm{G} 8^{-/-}$mice were smaller and less abundant than those in the wild-type animals, as judged by electron microscopy (Figure 1C).

The reduction in cholesterol content of the adrenal glands from $\mathrm{G} 5 \mathrm{G} 8^{-/-}$mice was quantified by gas chromatography-mass spectrometry (GC-MS). Total adrenal sterol content was reduced by $85 \%$ in female $\mathrm{G}_{5} \mathrm{G} 8^{-/-}$mice and by $76 \%$ in male $\mathrm{G} 5 \mathrm{G} 8^{-/-}$mice, as compared to wild-type controls (Figure 2 and Table 1). The decrease in sterol content was due to a reduction in the cholesterol content of the glands. The total cholesterol content of the adrenal glands in female and male mice was reduced $91 \%$ and $83 \%$, respectively. The cholesteryl ester content was $96 \%$ lower in female and 91\% lower in male G5G $8^{-1-}$ mice, whereas the free cholesterol con-

\section{Figure 1}

Comparison of the adrenal glands from female $\mathrm{G5G} 8^{-/-}$mice with those from female wild-type mice. (A) Adrenal glands from 6-monthold female wild-type and $G 5 G 8^{-1-}$ mice. (B) Sections from the adrenal cortex of a female wild-type mouse and a female $\mathrm{G} 5 \mathrm{~GB}^{-1-}$ mouse after staining with Oil-Red $O(\times 20$ magnification). (C) Electron micrographs of the adrenal zona fasciculata of wild-type and $G 5 G 8^{-/-}$mice. Adrenal glands were removed from 6-month-old female wild-type and $G 5 G 8^{-/-}$ mice, and electron microscopic sections were prepared and examined as described in Methods. Electron micrographs were taken at a magnification of $\times 2,500$. Scale bars: $1 \mu \mathrm{m}$.

tent of the adrenal glands was reduced by $62 \%$ and $46 \%$ in female and male $\mathrm{G} 5 \mathrm{G} 8^{-/-}$mice, respectively (Table 1 ). Thus, although ABCG5 and ABCG8 are not expressed in the adrenal gland (2), the cholesterol content of the glands was dramatically altered by the inactivation of the two half-transporters.

In contrast to the marked reductions in levels of cholesterol and cholesteryl esters in the adrenal glands of $G 5 G 8^{-/-}$mice, the levels of plant sterols in this organ were increased 2.4 fold in the female and 3.2 fold in the male G5G8 $8^{--}$mice (Table 1 and Figure 2). The increase in adrenal plant sterol levels was predominantly due to increases in free sitosterol and campesterol, which were roughly 53-fold and 8.5-fold higher, respectively, in the knockout mice compared to littermate controls. The amount of sitosteryl ester was increased ( 7 fold) in the knockout mice, whereas the amount of campesteryl ester was about $34 \%$ lower in $G 5 \mathrm{G}^{-/-}$mice versus wildtype animals. The levels of stigmasterol, another plant sterol that accumulates in tissues of the $G 5 G 8^{-1-}$ mice (7), were measured in a second group of female wild-type and knockout mice $(n=6$ in each group); the mean tissue levels of stigmasterol were 70 -fold higher in the knockout animals ( $4 \pm 0.7 \mu \mathrm{g} / \mathrm{g}$ vs. $263 \pm 34 \mu \mathrm{g} / \mathrm{g}$ of tissue).

ACAT and hormone-sensitive lipase activities were normal in the adrenal glands of the $\mathrm{G} 5 \mathrm{G} 8^{-1-}$ mice. To determine whether the lipid depletion of the adrenal glands in the $65 \mathrm{Gr}^{-/-}$mice was due to reduced ability to form sterol esters or to increased cholesteryl esterase activity,

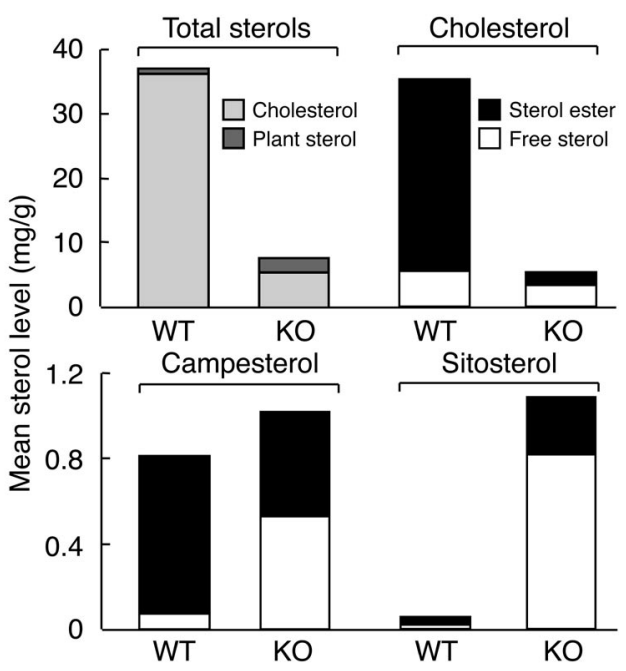

Figure 2

Adrenal sterol levels in $\mathrm{G}_{5} \mathrm{~GB}^{-/-}$and wild-type mice. Sterol concentrations were measured in pooled adrenal glands of 12-week-old female mice ( $n=4$ in each group) as described in Methods. The experiment was repeated twice, and the results were similar. 
Table 1

Sterol content in the adrenal gland of wild-type and $\mathrm{G} 5 \mathrm{G} 8^{-1-}$ mice

\begin{tabular}{|c|c|c|c|c|c|c|c|c|c|c|c|}
\hline \multirow[t]{2}{*}{ Treatment } & \multirow[t]{2}{*}{$\begin{array}{l}\text { Total sterols } \\
\qquad(\mathrm{mg} / \mathrm{g})\end{array}$} & \multirow[t]{2}{*}{$\begin{array}{l}\text { Plant sterol } \\
(\mathrm{mg} / \mathrm{g})\end{array}$} & \multicolumn{3}{|c|}{$\begin{array}{l}\text { Cholesterol } \\
(\mathrm{mg} / \mathrm{g})\end{array}$} & \multicolumn{3}{|c|}{$\begin{array}{c}\text { Campesterol } \\
(\mathrm{mg} / \mathrm{g})\end{array}$} & \multicolumn{3}{|c|}{$\begin{array}{l}\text { Sitosterol } \\
(\mathrm{mg} / \mathrm{g})\end{array}$} \\
\hline & & & Total & Free & Ester & Total & Free & Ester & Total & Free & Ester \\
\hline \multicolumn{12}{|l|}{ Female } \\
\hline WT & 36.21 & 0.87 & 35.34 & 5.45 & 29.89 & 0.81 & 0.07 & 0.74 & 0.06 & 0.02 & 0.04 \\
\hline G5G8-/- & 5.38 & 2.11 & 3.27 & 2.10 & 1.17 & 1.02 & 0.53 & 0.49 & 1.09 & 0.82 & 0.27 \\
\hline \multicolumn{12}{|l|}{ Male } \\
\hline WT & 20.86 & 0.44 & 20.42 & 3.71 & 16.71 & 0.40 & 0.04 & 0.36 & 0.04 & 0.01 & 0.03 \\
\hline G5G8-/- & 4.96 & 1.40 & 3.56 & 2.00 & 1.56 & 0.65 & 0.34 & 0.31 & 0.75 & 0.53 & 0.22 \\
\hline
\end{tabular}

Total sterols (cholesterol plus sitosterol and campesterol) and free and esterified sterols from pooled adrenal glands of 6-month-old male and 3-month-old female mice in each group $(n=4)$ were measured by gas chromatography, as described in Methods. Data are expressed as milligrams of sterol per gram of wet adrenal gland tissue.

we compared the enzymatic activities of ACAT and hormone-sensitive lipase (HSL) in the adrenal glands of the $\mathrm{G}_{5} \mathrm{G}^{-/-}$and wildtype animals. No significant differences between the two strains of mice were found in the activities of these enzymes (Figure 3).

$H M G-C o A$ reductase activity was reduced in the adrenal glands of the G5G $8^{-/-}$mice. To determine whether the markedly reduced levels of cholesterol in the adrenal glands of the $G 5 G 8^{-1-}$ mice resulted in an increase in endogenous cholesterol synthesis, we measured the activity of HMG-CoA reductase (HMGCR), the rate-limiting enzyme in cholesterol biosynthesis, in microsomes isolated from G5G8 $8^{--}$and wild-type mice. The activity of HMGCR was reduced $40 \%$ in the knockout animals (Figure 3 ). This observation is consistent with reductions seen in levels of two biosynthetic precursor sterols in the $\mathrm{G5} \mathrm{G}^{-{ }^{--}}$adrenal glands: a 58\% reduction in lathosterol (see below) and a $47 \%$ reduction in desmosterol (data not shown). This is also consistent with our previous finding that the rate of cholesterol synthesis in the adrenal glands of the knockout animals was reduced by $40 \%$ (6). Thus, the reduction in the cholesterol content of the adrenal glands failed to stimulate an increase in cholesterol synthesis in the $G 5 G 8^{-/-}$mice.

Comparison of selected $m R N A$ s and proteins involved in sterol metabolism in $\mathrm{G}_{5} \mathrm{G}^{-/-}$and wild-type mice. Despite the $>90 \%$ reduction in the cholesterol content of the $G 5 \mathrm{Gr}^{-/-}$adrenal glands, there were either no changes or reduced mRNA levels of SREBP-2 and several enzymes of the cholesterol biosynthetic pathway, including HMGCR, HMG-CoA synthase (HMGCS), farnesyl diphosphate synthase (FPPS) and squalene synthase (Figure 4A). The mRNA levels of SREBP-1c and $A B C A 1$, which are target genes for the nuclear hormone receptor, liver X receptor $(L X R)(22,23)$, were increased 2-fold. However, no significant differences were found in the mRNA levels of either fatty acid synthase (FAS) or stearoyl CoA desaturase (SCD), which are also upregulated in response to LXR agonists in other tissues $(24,25)$. In addition, no changes were found in the mRNA levels of SR-BI or the LDLR (Figure 4A).

Next, we compared the levels of immunodetectable SR-BI, LDLR, and ABCA1 in the adrenal glands from the $G 5 \mathrm{Gr}^{-/-}$and wild-type mice (Figure 4B). No changes were found in the protein levels of either lipoprotein receptor, whereas ABCA1 levels were 10 -fold higher in the adrenal glands of the $G 5 \mathrm{GS}^{-/-}$mice. There was a greater increase in immunodetectable ABCA1 than in ABCA1 mRNA in the same tissue, suggesting a post-transcriptional effect of plant sterol accumulation on ABCA1 (Figure 4B).
Response to acute ACTH stimulation is normal in $\mathrm{G} 5 \mathrm{G} 8^{-1-}$ mice. To determine whether the depletion of cholesteryl esters compromised the ability of the adrenal gland to respond to stress, we challenged $\mathrm{GSG}^{-/-}$mice with ACTH and measured the resulting increase in circulating corticosterone, the major corticosteroid in mice. No significant differences were found between $G 5 G 8^{-1-}$ and wild-type mice in either the basal or stimulated levels of plasma corticosterone (Figure 5A). The plasma levels of corticosterone increased by $\sim 133 \%$ in the wild-type mice and $148 \%$ in the $65 \mathrm{G}^{-1-}$ mice after treatment with ACTH. Thus, despite the very low levels of cholesterol in the $\mathrm{G} 5 \mathrm{G} 8^{-1-}$ adrenal glands, these mice had sufficient steroidogenic capacity to maintain a normal response to an acute ACTH stimulus (Figure 5A).

Sterol accumulation in the adrenals of dexamethasone-treated mice. To determine whether inhibition of steroidogenesis in the adrenal glands of $\mathrm{G} \mathrm{G} 8^{-/-}$mice restored sterol accumulation, the mice were treated with dexamethasone $(160 \mu \mathrm{g} /$ day $)$ for 6 days. Treatment resulted in a 2.5 -fold increase in the cholesterol content of the adrenal glands of the $G 5 \mathrm{G}^{-1-}$ mice, although both the free and esterified cholesterol content of the tissues remained significantly reduced when compared to the untreated wild-type mice (Figure 5B). Dexamethasone treatment was associated with significant increases in plant sterol esters and cholesteryl esters, in the adrenal glands of
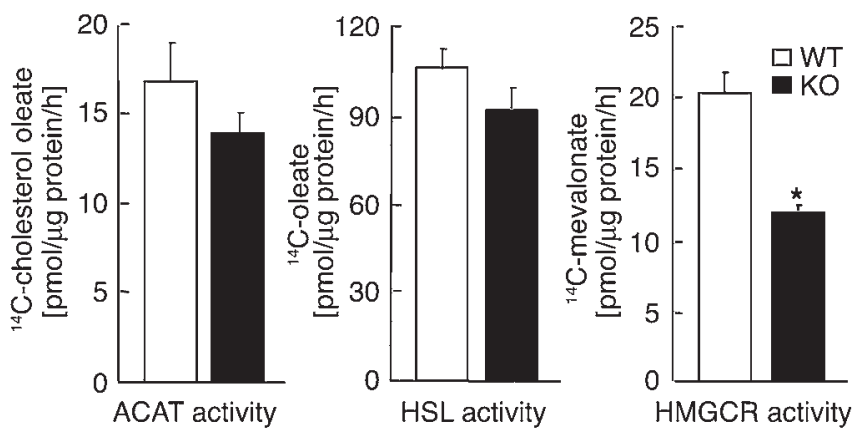

\section{Figure 3}

The activities of ACAT, HSL, and HMGCR in adrenal glands of wildtype and $\mathrm{GSG}^{-/-}$mice. Adrenal homogenates and microsomes were prepared from pooled adrenal glands of 12 -week-old female mice $(n=6$ in each group). The assays were performed in triplicate on two occasions. Values are means \pm SEM. 
A

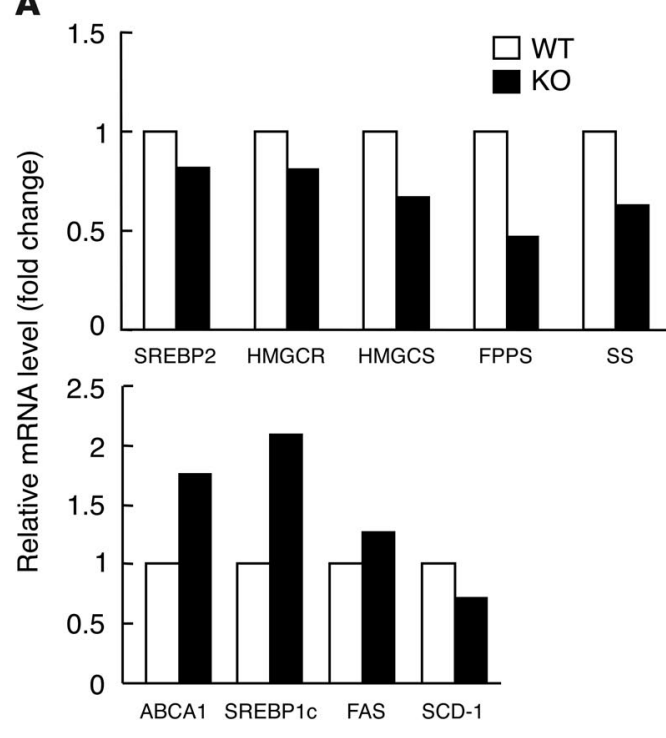

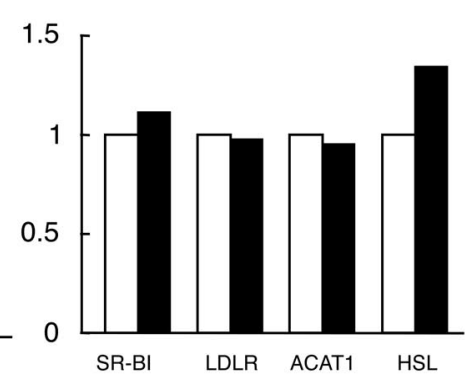

B

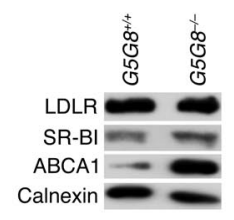

Figure 4

Expression levels of selected genes and proteins involved in lipid metabolism in $\mathrm{G} 5 \mathrm{G}^{-/-}$mice. (A) Relative mRNA levels in adrenal glands of wild-type and $G 5 G 8^{-/-}$mice. Total RNA was extracted from pooled adrenal glands of 6-month-old female wild-type and G5G8 $8^{-1-}$ mice $(n=5$ in each group) and quantified by real-time PCR as described in Methods using cyclophilin as an internal control. Values are expressed relative to those of chow-fed wild-type mice, which were arbitrarily standardized to 1 . The experiment was also performed using adrenal glands from male mice and the results were similar. SS, squalene synthase. (B) Protein levels of LDLR, SR-B1, and ABCA1 in the adrenal glands of wild-type and $\mathrm{G}_{5} \mathrm{G}^{-/-}$mice. Adrenal membrane proteins were prepared from pooled adrenal glands of 6-month-old male wild-type and $\mathrm{GSG}_{5} \mathrm{~F}^{-/}$ mice ( $n=4$ in each group) and immunoblotted with antibodies to LDLR, SR-BI, and ABCA1 as described in Methods. Filters were re-probed with various antibodies after stripping.

the $\mathrm{G} 5 \mathrm{G} 8^{-/-}$mice. Thus, feedback inhibition of steroidogenesis by treatment with a potent corticosteroid resulted in the accumulation of sterols in both wild-type and $\mathrm{G} 5 \mathrm{G} 8^{-1-}$ mice.

The cholesterol content of the G5G8 ${ }^{-1-}$ adrenal glands increases in response to treatment with the sterol absorption inbibitor ezetimibe. The depletion of adrenal cholesterol in $G 5 G 8^{-1-}$ mice may be caused by accumulation of dietary sterols in the adrenal cells. To test this hypothesis, we treated $\mathrm{G} 5 \mathrm{G} 8^{-/-}$mice for one month with ezetimibe (SCH58235), an inhibitor of sterol absorption (26). Ezetimibe treatment resulted in a 50\% reduction in the sitosterol and campesterol content of the adrenal glands of knockout animals and a significant increase in the concentration of adrenal cholesterol (from $8.6 \mathrm{mg} / \mathrm{g}$ to $31.2 \mathrm{mg} / \mathrm{g}$ ) (Figure 6). Ezetimibe treatment also increased the levels of the cholesterol biosynthetic precursor sterols lathosterol (Figure 6), desmosterol, and lanosterol (data not shown) in adrenal glands of the knockout animals. These data are consistent with the notion that cholesterol depletion of the adrenal glands in the $\mathrm{GSG}^{-/-}$mice resulted from the accumulation of a dietary constituent, presumably plant sterols, that inhibits cholesterol synthesis and whose uptake is inhibited by ezetimibe.

Suppression of HMGCR by phytosterols in cultured adrenal cells. To determine if the accumulation of a specific dietary plant sterol(s) caused the reduction in cholesterol synthesis, we examined the effects of selected plant sterols on HMGCR levels in cultured adrenocortical cells (Y1-BS1 cells). A total of $50 \mu \mathrm{g} / \mathrm{ml}$ of cholesterol, sitosterol, campesterol, stigmasterol, or brassicasterol dissolved in ethanol was added to the culture medium and incubated with the adrenal cells for 24 hours (Figure 7A). HMGCR levels were unchanged in cells treated with ethanol alone, and were reduced to undetectable levels in cells treated with 25-hydroxycholesterol, a potent inhibitor of cholesterol synthesis. Significant reductions in the levels of HMGCR were detected in cells treated with cholesterol, campesterol, and stigmasterol, but not in cells treated with sitosterol. A modest decrease in HMGCR was seen in the cells treated with brassicasterol. The changes observed in HMGCR levels were not attributable to differences in the amount of the various sterols that entered the cells. The highest cellular concentration of phytosterols was seen in the sitosterol-treated cells $(11.2 \pm 3.8 \mu \mathrm{g} / \mathrm{mg}$ protein), and the lowest level was seen in cells treated with brassicasterol $(3.1 \pm 0.6 \mu \mathrm{g} /$ mg protein). The cellular levels of campesterol and stigmasterol were intermediate between these extremes $(7.3 \pm 1.9 \mu \mathrm{g} / \mathrm{mg}$ and $6.1 \pm 2.2 \mu \mathrm{g} / \mathrm{mg}$ protein, respectively). The cellular differences in response to the various plant sterols were not attributable to secondary effects of the phytosterols on the cellular content of cholesterol. No significant differences in the cholesterol levels in the cells treated with sitosterol, campesterol, stigmasterol, or brassicasterol were detected $(21.6 \pm 0.8,21.2 \pm 0.6,21.5 \pm 0.5$, and $19.3 \pm 1.6$ $\mu \mathrm{g} / \mathrm{mg}$ protein, respectively). Thus, treatment of cells with some, but not all, plant sterols was associated with significant reductions in HMGCR levels that were not due to changes in cholesterol levels.

Stigmasterol induces a dose-dependent reduction in HMGCR protein in Y1-BS1 cells. A detectable reduction in HMGCR protein was apparent within 6 hours of adding stigmasterol to the medium of the cultured adrenal cells; within 24 hours, HMGCR had fallen to very low levels (Figure 7C). Next, we calculated the dose-response relationship between stigmasterol concentration and HMGCR levels (Figure 7D). A greater than 50\% reduction in HMGCR levels was seen with $25 \mu \mathrm{g} /$ $\mathrm{ml}$ of stigmasterol treatment, and increasing levels of stigmasterol were associated with a progressive decrease in HMGCR levels.

Reduction of cholesterol synthesis in stigmasterol-treated Y1-BS1 cells. To determine if the reduction in HMGCR protein was associated with a reduction in other cholesterol-regulated genes, we examined the effect of stigmasterol treatment on mRNA levels for three genes in the cholesterol biosynthetic pathway - HMGCR, HMGCS, and FPPS - as well as on the level of LDLR mRNA. (Figure 8A). The levels of all four of these transcripts were reduced in a dose-dependent fashion when stigmasterol was added to the medium.

Consistent with the reductions in the mRNA levels of multiple enzymes in the cholesterol biosynthetic pathway, cholesterol synthesis was found to be markedly reduced in the cells treated with stigmasterol (Figure 8B). These results suggested that stigmasterol may interfere with the cholesterol regulatory machinery in cells. To test this hypothesis, we examined the processing of SREBP-2 in cultured adrenal cells treated with sitosterol, campesterol, or stigmasterol (Figure 9). Under cholesterol-depleted conditions, most of 

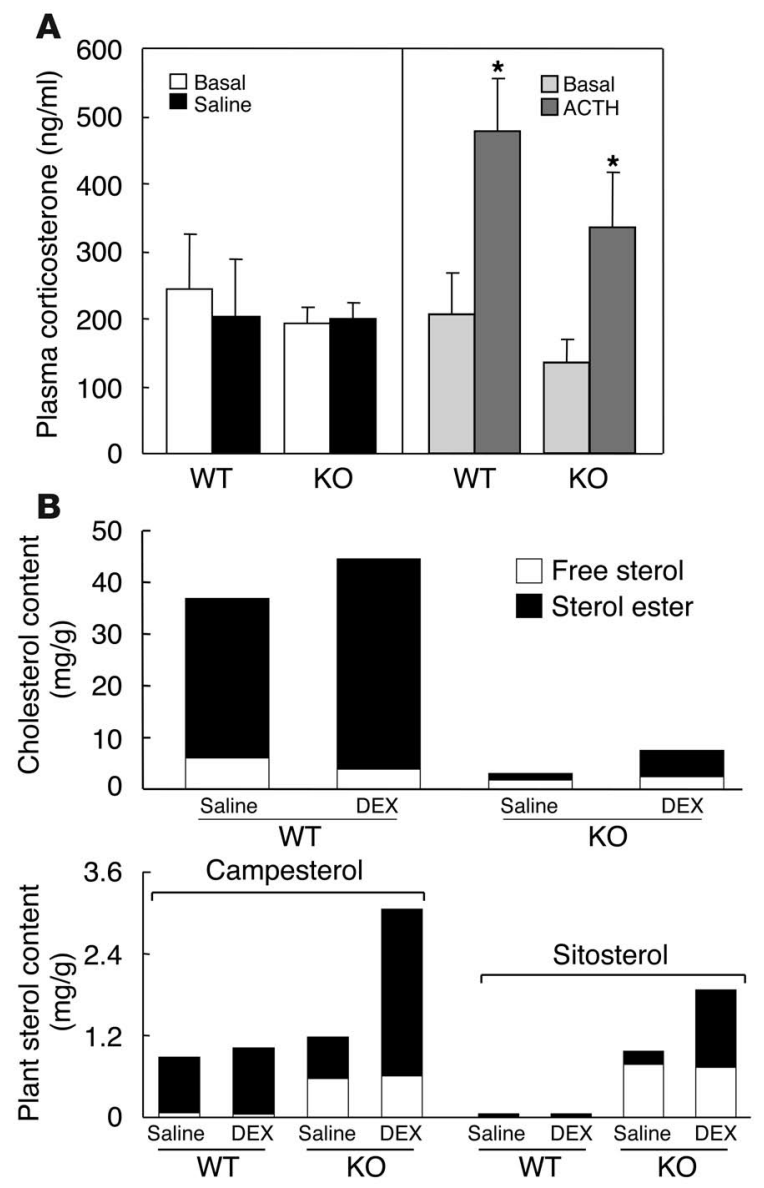

the SREBP-2 in the ER undergoes proteolytic processing to mature SREBP-2 (27). Mature SREBP-2 enters the nucleus and stimulates expression of genes encoding enzymes in the cholesterol biosynthetic pathway (27). Treatment with 25 -hydroxycholesterol plus cholesterol completely inhibited SREBP-2 processing, whereas sitosterol had no effect on the amount of mature SREBP-2 produced. Stigmasterol almost completely inhibited processing of the transcription factor, whereas campesterol had a more modest inhibitory effect (Figure 9). These results are consistent with an inhibitory effect of plant sterols on SREBP-2 processing, which would contribute to the reduction in cholesterol synthesis in the adrenal glands of the $\mathrm{G}^{\mathrm{G}} \mathrm{G8}^{-/-}$mice.

\section{Figure 5}

Changes in adrenal steroids in $\mathrm{G}_{5} \mathrm{G8}^{-/-}$mice in response to ACTH and dexamethasone. (A) Serum corticosterone levels in response to ACTH stimulation in wild-type and $G 5 G 8^{-/-}$mice ( $n=4$ per group). ${ }^{\star} P<0.05$, basal vs. ACTH. (B) The sterol content of adrenal glands in wild-type and $\mathrm{G}_{5} \mathrm{G}^{-/-}$mice, before and after dexamethasone (DEX) treatment $(n=4$ per group). Values are means \pm SEM of measurements made in triplicate.

Next we examined whether the increased ABCA1 expression in the adrenal gland is due to activation of LXR by plant sterols. Using a reporter gene assay, we compared the effect of sitosterol and stigmasterol on LXR activation in CHO-7 cells. A potent synthetic LXR agonist, T0901317, increased LXR-mediated transcription 16 fold; the activation was inhibited by addition of arachidonate, an LXR antagonist (28). Addition of sitosterol $(25 \mu \mathrm{g} / \mathrm{ml})$ failed to stimulate LXR-mediated luciferase expression in the same assay. In contrast to sitosterol, stigmasterol treatment $(25 \mu \mathrm{g} / \mathrm{ml})$ was associated with a 5 -fold increase in luciferase expression, and this increase in expression was inhibited by the addition of arachidonate.

\section{Discussion}

In this paper we show that accumulation of plant sterols in the adrenal glands of $\mathrm{G5} \mathrm{G8}^{-/-}$mice profoundly alters adrenal cholesterol homeostasis. Despite the marked increase in both the free and esterified plant sterol content of the adrenal glands, total sterol content (cholesterol plus plant sterols) was reduced by more than $75 \%$ in the $G 5 G 8^{-/-}$mice. The reduction in adrenal sterol content was predominantly due to a reduction in cholesteryl esters, although free cholesterol levels were also significantly reduced. The low cholesterol content of the adrenal glands in the $\mathrm{G} 5 \mathrm{G} 8^{-1-}$ mice failed to elicit an increase in the levels of enzymes catalyzing de novo cholesterol synthesis or in the levels of the lipoprotein receptors that mediate cholesterol uptake. Protein levels of ABCA1, a mediator of cholesterol efflux from cells, were increased 10 fold in the adrenal glands of the $G 5 \mathrm{~GB}^{-/-}$mice, implicating a paradoxical increase in sterol efflux as a contributing factor to sterol depletion. Ezetimibe treatment, which inhibits sterol absorption, increased the cholesterol content of the adrenal gland, indicating that the accumulation of plant sterols was responsible for altered cholesterol homeostasis in the adrenal glands of the $\mathrm{GSG}^{-/-}$mice.

Since ABCG5 and ABCG 8 mRNAs are not present in the adrenal glands of normal mice (2), the alterations in the appearance and sterol content of the adrenal glands of the $\mathrm{GSG}^{-1-}$ mice are

\section{Figure 6}

Adrenal sterol content in wild-type and $\mathrm{G5G8}^{-/-}$mice treated with ezetimibe (0.005\% for 1 month). The data are mean \pm SEM of each group $(n=6) .{ }^{* *} P<0.000001$, chow vs. ezetimibe.
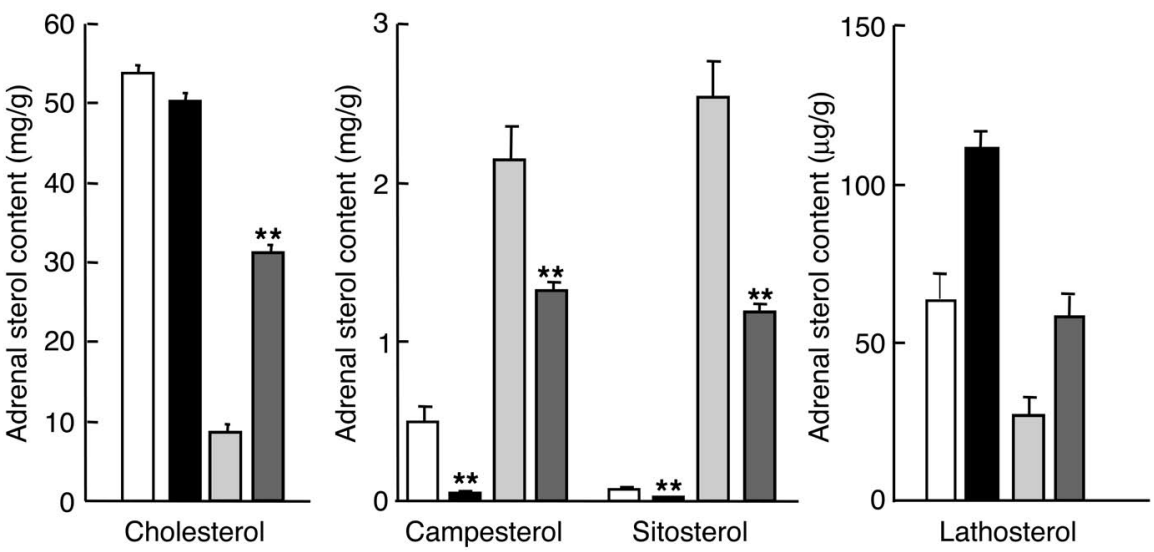


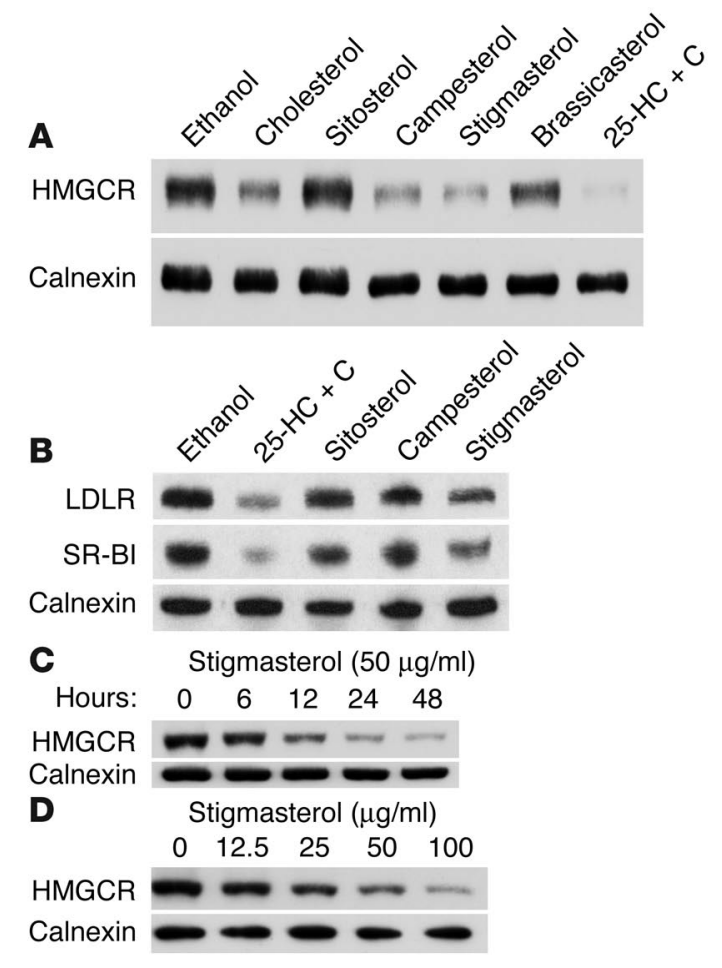

not due to a local deficiency of these proteins. Thus the severe lipid depletion of the adrenal glands in the $G 5 G 8^{-1-}$ mice is a secondary effect of ABCG5 and ABCG8 deficiency, most likely due to the accumulation of noncholesterol sterols. Consistent with this notion, ezetimibe treatment limited the accumulation of noncholesterol sterols and increased adrenal cholesterol to nearnormal levels in the $\mathrm{G} 5 \mathrm{G} 8^{-/-}$mice.

The accumulation of plant sterols may lead to depletion of adrenal cholesterol by several mechanisms. Circulating HDL is the major source of adrenal sterols in rodents (9), and plasma HDL-C levels are decreased by $\sim 40 \%$ in the G5G $8^{-1-}$ mice (6). The reduction in adrenal sterol levels cannot be attributed solely to a reduction in circulating lipoprotein concentrations, however, since even larger reductions in circulating HDL are not associated with changes in adrenal cholesterol content in Apoa2 knockout mice (17). Genetic defects that limit the uptake of HDL-C, includ-

\section{Figure 7}

Effects of cholesterol and noncholesterol sterols on HMGCR, LDLR, and SR-BI protein levels in Y1-BS1 cells. (A) Y1-BS1 cells were plated on day $0\left(0.4 \times 10^{6}\right.$ cells per well $)$ in 6 -well plates and grown in medium A. On day 3, the medium was switched to DMEM/F12 plus $10 \%$ NCLPPS, $50 \mu \mathrm{M}$ mevalonate, and $50 \mu \mathrm{M}$ compactin. After 16 hours, sterols were added in ethanol at either $50 \mu \mathrm{g} / \mathrm{ml}$ for cholesterol, sitosterol, stigmasterol, and bassicasterol or $1 \mu \mathrm{g} / \mathrm{ml}$ for 25-hydroxycholesterol plus $10 \mu \mathrm{g} / \mathrm{ml}$ cholesterol $(25-\mathrm{HC}+\mathrm{C})$. After 24 hours, the cells were harvested and cell lysates were prepared. Immunoblot analysis was performed using a monoclonal antibody to HMGCR as described in Methods. (B) Membranes were isolated from the cells, and $60 \mu \mathrm{g}$ of protein was subjected to immunoblotting using anti-LDLR and SR-BI antibodies as described in the Methods. (C) On day 3 , the medium was switched to DMEM/F12 plus $10 \%$ NCLPPS, $50 \mu \mathrm{M}$ compactin, and $50 \mu \mathrm{M}$ mevalonate. After 16 hours, $50 \mu \mathrm{g} / \mathrm{ml}$ of stigmasterol was added in ethanol and cells were incubated for the indicated times. (D) On day 3, the medium was switched to DMEM/F12 plus $10 \%$ NCLPPS, $50 \mu \mathrm{M}$ compactin, and $50 \mu \mathrm{M}$ mevalonate. After 16 hours, stigmasterol was added at the doses indicated. Cells were incubated for 24 hours. Lysates were prepared and immunoblotted for HMGCR. The final concentrations of ethanol were $1 \%(\mathbf{A}-\mathbf{C})$ or $2 \%$ (D).

ing deficiency of apoAI (17) and SR-BI (19), have major effects on adrenal cholesterol homeostasis. Could the enrichment of circulating HDL particles with plant sterols in the $\mathrm{G5} \mathrm{G}^{-/-}$mice interfere with the selective uptake process? The movement of sterols from HDL into the adrenocortical cells is mediated by SR-BI and occurs in a specialized series of microvillar channels (29). The expression of SR-BI was normal in the $G 5 \mathrm{G}^{-/-}$mice, and inspection of their microvillar channels by electron microscopy failed to reveal gross structural changes that might interfere with sterol transport into the adrenal cells (data not shown). Furthermore, the accumulation of plant sterols in the adrenal glands of the G5G8 ${ }^{-1-}$ mice suggests that the receptor-mediated mechanisms for sterol uptake into the adrenal cells remain intact.

Depletion of adrenal cholesterol may also be caused by a diminished capacity to store cholesterol, or by accelerated loss of cholesterol either by conversion to adrenal steroids or by direct secretion. Adrenal cholesterol content is markedly reduced in mice lacking Acat1 (21), which encodes the form of ACAT expressed in the adrenal gland, but adrenal ACAT activity was normal in $\mathrm{GSG}^{-/-}$mice. Treatment with dexamethasone to suppress adrenal sterol formation did not restore adrenal cholesterol levels in $\mathrm{G}_{5} \mathrm{Gr}^{-/-}$mice.

\section{Figure 8}

Effect of stigmasterol on mRNA levels $(\mathbf{A})$ and cholesterol synthesis (B) in Y1-BS1. (A) Y1-BS1 cells were plated and treated with stigmasterol for 24 hours as indicated. Messenger RNA levels were quantified by real-time PCR as described in Methods. Values were expressed relative to untreated samples, which were arbitrarily standardized to 1 . The experiment was repeated twice and similar results were obtained. (B) Y1-BS1 cells were treated with stigmasterol $(50 \mu \mathrm{g} / \mathrm{ml})$ or sterols $(1 \mu \mathrm{g} / \mathrm{ml} 25$-hydroxysterol plus $10 \mu \mathrm{g} / \mathrm{ml}$ cholesterol; $25-\mathrm{HC}+\mathrm{C}$ ) for 24 hours. Cholesterol synthesis was measured by ${ }^{14} \mathrm{C}$ acetate incorporation as described in Methods.

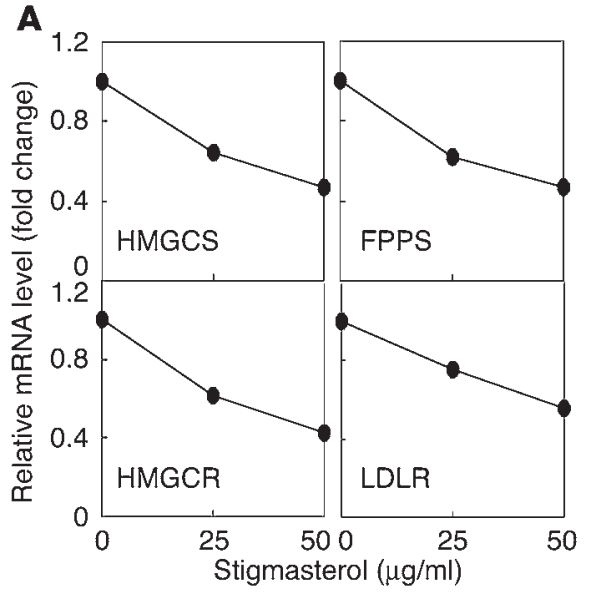

B

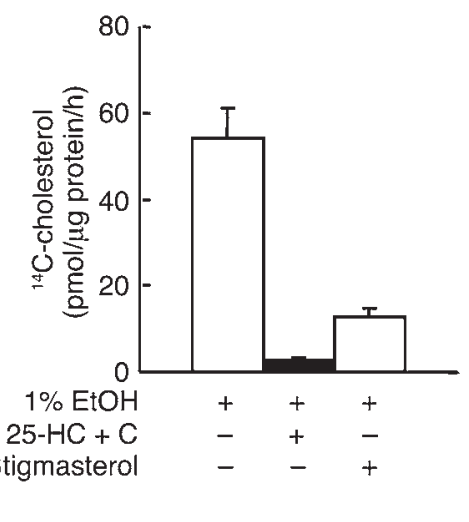




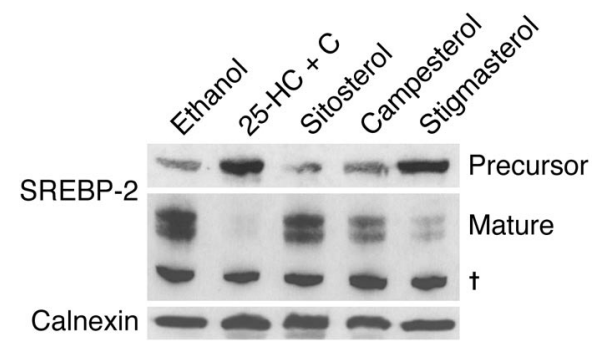

\section{Figure 9}

Effect of phytosterol on SREBP processing in Y1-BS1 cells. Y1-BS1 cells were plated on day 0 at a density of $1 \times 10^{6}$ cells $/$ dish in $10 \mathrm{~cm}$ dishes and treated as described in the legend to Figure 7 . The cells were treated with the various sterols for 24 hours $(50 \mu \mathrm{g} / \mathrm{ml}$ sitosterol, campesterol, stigmasterol, or $25-\mathrm{HC}+\mathrm{C}$ [ $3 \mu \mathrm{g} / \mathrm{ml} 25$-hydroxycholesterol plus $10 \mu \mathrm{g} / \mathrm{ml}$ cholesterol]). The membrane and nuclear fractions were prepared and subjected to immunoblot analysis with a rabbit anti-mouse polyclonal anti-SREBP-2 antibody. The experiment was replicated once and showed a similar result. ${ }^{\dagger}$ Nonspecific bands of an unknown protein.

Therefore the depletion of adrenal sterols in $\mathrm{G} 5 \mathrm{G8^{-/- }}$ mice is not due to an increase in the conversion of cholesterol to adrenal steroids. We did not directly measure the rates of efflux of adrenal cholesterol in this study, but the level of ABCA1, a protein that mediates cholesterol efflux, was approximately 10 -fold higher $\mathrm{n}$ the adrenal glands of the $G 5 \mathrm{G}^{-/-}$mice than in their wild-type littermates. There is compelling evidence that ABCA1 transports sitosterol as well as campesterol (30). The increased levels of $\mathrm{ABCA} 1$ protein in the adrenal gland of the $\mathrm{G} 5 \mathrm{G} 8^{-/-}$mice may contribute to the cholesterol depletion by enhancing efflux of sterols from the adrenocortical cells.

The stimulus for upregulation of ABCA1 in the adrenal gland of G5G8 $8^{-/}$mice is not known, but is presumed to be either a direct effect of the one of the plant sterols or an indirect effect of these sterols on cholesterol metabolism. ABCA1 is a target gene of the nuclear receptor $\operatorname{LXR}(22,30,31)$. Cholesterol, or the administration of the potent LXR agonist T0901317, increases expression of ABCA1 in the small intestines and livers of mice (32). The paradoxical upregulation of ABCA1 in the adrenal cells, in which the levels of cholesterol are low, suggests that one of the plant sterols that accumulates in the tissues of the $G 5 \mathrm{G}^{-/-}$mice may be a direct LXR agonist. Using a luciferase reporter assay, we found that stigmasterol, but not sitosterol, activates LXR- $\alpha$, suggesting that stigmasterol may be the endogenous ligand responsible for increasing ABCA1 expression in the $G 5 G^{-1-}$ mice. This finding is consistent with a previous observation that the phytosterol-derived compound YT-32 is an LXR agonist (33). Alternatively, the accumulation of plant sterols may promote the generation of another agonist that results in increased expression of ABCA1, for example by stimulating adenosine $3^{\prime}, 5^{\prime}$-cyclic monophosphate (cAMP) (34) or by inhibiting geranylgeranyl transferase (35).

Interestingly, the increase in ABCA1 protein was greater than the increase in ABCA1 mRNA, suggesting a posttranscriptional effect on ABCA1. Moreover, addition of stigmasterol to cultured adrenal cells resulted in an increase in ABCA1 mRNA, although we were not able to detect any ABCA1 protein with our antibody (data not shown). ABCA1 has a protein sequence rich in proline, glutamic acid, serine, and threonine (PEST sequence) site, and degradation of the protein is affected by binding to apoAl ligand, as well as by changes in the lipid composition of the membrane (36-38). Further studies will be required to examine the effects of plant sterols on ABCA1 half-life.

Although the cholesterol content of the adrenals was dramatically reduced, the expression profiles of cholesterol-regulated genes and proteins in the $G 5 \mathrm{G}^{-/-}$adrenals were consistent with the adrenal cells being cholesterol replete. Other genetic perturbations that result in cholesteryl ester-depleted adrenal glands stimulate counter-regulatory responses that increase the endogenous synthesis and import of cholesterol by upregulating HMGCR, SR-BI, and LDLR $(17,39-41)$. For example, the adrenal glands of apoAI ${ }^{-/-}$mice have a more than 5-fold increase in HMGCR activity and a more than 2-fold increase in LDLR levels compared to wild-type controls (17). In contrast to these findings, no increases in SR-BI or LDLR mRNA or protein levels were seen in the adrenal glands of the $\mathrm{G} 5 \mathrm{G}^{-1-}$ mice. Nor was an increase in de novo cholesterol synthesis observed, as measured directly (6) or as reflected in the levels of mRNA for enzymes in the cholesterol biosynthetic pathway (Figure 4) or the levels of cholesterol biosynthetic precursors in the adrenal glands of the $\mathrm{G} 5 \mathrm{G} 8^{-/-}$mice.

The mRNA levels of all the genes in the cholesterol biosynthesis pathway were reduced in the livers of $G 5 G 8^{-/-}$mice (7), suggesting that plant sterols exert their inhibitory effect on cholesterol synthesis at the level of transcription. Plant sterols may also directly inhibit the activity of one or more of the enzymes in the cholesterol biosynthetic pathway or enhance the degradation of those enzymes in the adrenal cells. Field and coworkers (42) reported previously that sitosterol reduces HMGCR activity, mRNA levels, and protein levels in the intestine-derived cell line CaCO-2. In fibroblasts, both sitosterol and campesterol have modest effects on HMGCR activity (43). In our studies of cultured adrenal cells, HMGCR protein levels were not affected by sitosterol but were significantly reduced by stigmasterol, the $\Delta 22$ derivative of sitosterol, and campesterol, which has a methyl rather than an ethyl group at C24. We then

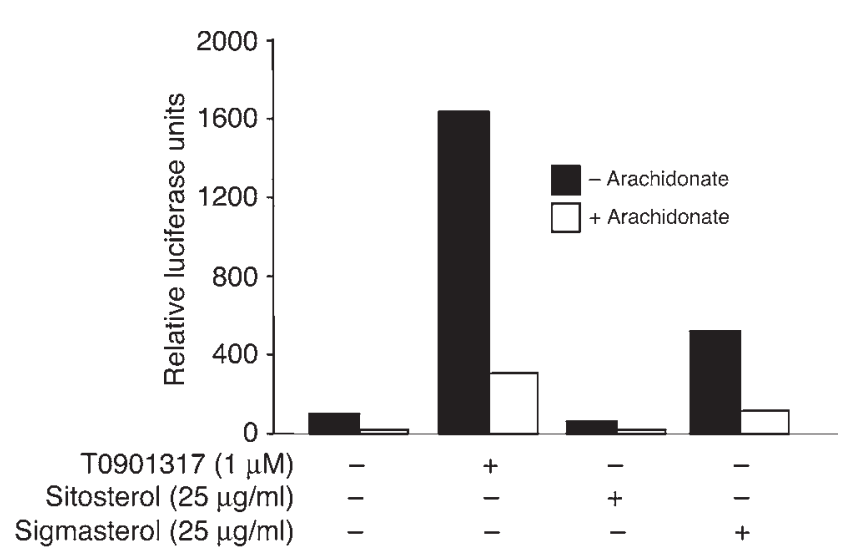

\section{Figure 10}

Effect of plant sterols on LXR-luciferase reporter activity in $\mathrm{CHO}-7$ cells. CHO-7 cells were plated on day 0 at a density of $2 \times 10^{5}$ cells in 6 -well plates. On day one, cells were cotransfected with $\mathrm{pCMX} / \mathrm{Gal} 4$ LXR- $\alpha(0.26 \mu \mathrm{g} / \mathrm{well})$ and pMH100X4-TK-luc $(0.88 \mu \mathrm{g} / \mathrm{well})$ and pCMX$\beta$ Gal $(0.5 \mu \mathrm{g} /$ well). Cells were incubated in growth medium containing $50 \mu \mathrm{M}$ compactin and $5 \mu \mathrm{M}$ mevalonate as described in Methods. After 16 hours the luciferase activities were assayed as described in Methods. The experiment was performed 3 times and the values shown are the results of a representative experiment. 
showed that stigmasterol, and to a lesser extent campesterol, interferes with SREBP cleavage (44). The levels of stigmasterol required to demonstrate a reduction in HMGCR protein were similar to those measured in the circulation of $\mathrm{G} 5 \mathrm{G} 8^{-/-}$mice (7), which suggests that the accumulation of this sterol may contribute to altered cholesterol homeostasis in the $\mathrm{GSG}^{-/-}$mice. Future studies will be required to determine the exact mechanism by which the accumulation of non-cholesterol dietary sterols interferes with the cholesterol regulatory machinery.

Surprisingly, despite the scant stores of cholesteryl esters and the reduced levels of endogenous cholesterol synthesis in the adrenal glands of the knockout mice, the ability of the glands to respond acutely to ACTH was unimpaired. Both campesterol and sitosterol are substrates for the side-chain cleavage reaction, the first committed step in steroidogenesis (45-47). Thus, the plant sterols may be used as a substrate for steroid synthesis in the adrenal glands of the $G 5 \mathrm{G}^{-/-}$mice. Only a single patient with sitosterolemia has undergone an autopsy (48), but unfortunately the adrenal glands were not analyzed. Therefore, it is not known whether humans with sitosterolemia have lipid-depleted adrenal glands. No reports of adrenal insufficiency or infertility have been described in patients with sitosterolemia, although it remains possible that adrenal insufficiency has contributed to the death of some patients with sitosterolemia presumed to have died from a cardiac event.

The findings reported here provide insights into the mechanism responsible for the very low rates of cholesterol synthesis found in individuals with sitosterolemia, even those who are normocholesterolemic (5). Our data indicate that accumulation of stigmasterol, and perhaps other bioactive sterols, downregulates the cholesterol regulatory machinery, resulting in reduced cholesterol biosynthesis. Consistent with this scenario is our finding that ezetimibe treatment was associated with a significant increase in cholesterol synthesis, as reflected by increased lathosterol levels, in the adrenal gland of the $G 5 \mathrm{Gr}^{-/-}$mice (Figure 6). It is of interest that tissue levels of lathosterol were also increased in the adrenal glands of the ezetimibe-treated wild-type mice, despite the low tissue levels of phytosterols at baseline. Further reduction of plant sterol levels was associated with a significant increase in tissue lathosterol levels. Plasma levels of plant sterols vary over a wide range in normal individuals (63), and these differences may affect cholesterol metabolism and contribute to individual differences in responsiveness to ezetimibe and other lipid-lowering agents.

\section{Methods}

Materials. Sterols were from Sigma-Aldrich or Steroloids Inc. Methyl- $\beta$ cyclodextrin, phosphatidylcholine, cholesteryl oleate, oleoyl CoA, HMG CoA, mevalonolactone, ACTH 1-24, dexamethasone (DEX, water soluble), glucose 6-phosphate, NADPH, glucose-6-phosphate dehydrogenase, and arachidonic acid were from Sigma-Aldrich. T0901317 was purchased from Cayman Chemical Co., $\left[1-{ }^{14} \mathrm{C}\right]$ oleoyl CoA, cholesteryl- $\left[1-{ }^{14} \mathrm{C}\right]$ oleate, $[9,10-$ $\left.{ }^{3} \mathrm{H}(\mathrm{N})\right]$ oleic acid, DL-3-hydroxy-3-methyl $\left[3-{ }^{14} \mathrm{C}\right]$ glutaryl CoA, RS- $\left[5-{ }^{3} \mathrm{H}\right]$ mevalonolactone, $\left[1-{ }^{14} \mathrm{C}\right]$ acetate, and $\left[1,2-{ }^{3} \mathrm{H}(\mathrm{N})\right]$ cholesterol were from American Radiolabeled Chemicals Inc. Polyclonal antibodies to bovine LDLR (49), SR-BI (50), and SREBP-2 (51), as well as a monoclonal antibody (IgG-A9) to HMGCR (52), were generated as described previously. Polyclonal anti-calnexin antibody was obtained from Stressgen Biotechnologies Corp., and anti-ABCA1 antiserum was kindly provided by Mason Freeman (Massachusetts General Hospital) (53). Ezetimibe was provided by Harry C. Davis, Jr. at the Schering-Plough Research Institute.
Animals and cell culture. G5G8 $8^{-/-}$mice were generated and maintained as described (6). All animal procedures were performed with the approval of the Institutional Animal Care and Research Advisory Committee at the University of Texas Southwestern Medical Center. Y1-BS1 cells, a cell line from a mouse adrenocortical tumor, were maintained in medium A (1:1 mixture of DMEM and Ham's F-12 medium, containing $100 \mathrm{U} / \mathrm{ml}$ penicillin and $100 \mu \mathrm{g} / \mathrm{ml}$ streptomycin sulfate) supplemented with $15 \%$ horse serum and $2 \% \mathrm{FCS}$ and grown at $37^{\circ} \mathrm{C}$ in $8-9 \% \mathrm{CO}_{2}$. CHO-7 cells were grown in medium A supplemented with $5 \%$ newborn calf lipoprotein-poor serum (NCLPPS) under the same conditions.

Tissue preparation and electron microscopy. Mice were anesthetized by an intraperitoneal injection of pentobarbital ( $30 \mathrm{mg} / \mathrm{kg}$ body weight) and the adrenal glands were quickly removed and minced into small pieces. The specimens were immersion-fixed in $2 \%(\mathrm{vol} / \mathrm{vol})$ glutaraldehyde in Hanks' balanced salt solution (20 mM HEPES, $\mathrm{pH}$ 7.4), rinsed twice in PBS buffer ( $10 \mathrm{mM}$ phosphate, $0.15 \mathrm{M} \mathrm{NaCl}, \mathrm{pH} 7.3$ ) and then postfixed in $1 \%$ osmium tetroxide in PBS buffer for 60 minutes, followed by extensive washing with distilled water. The specimens were then subjected to a series of ethanol dehydrations and embedded in Embed 812 (Electron Microscopy Sciences). Ultrathin sections $(\sim 80 \mathrm{~nm})$ were cut with a diamond knife using a Leica Ultracut R ultramicrotome, placed on Formvar/carbon-coated nickel grids (Electron Microscopy Sciences), and stained with $3 \%$ aqueous uranyl acetate (15 minutes) and lead acetate (5 minutes). The sections were examined using a JEOL1200 EX transmission electron microscope (JEOL Ltd.) operating at $80 \mathrm{kV}$, and electron micrographs were taken at a magnification of $\times 2,500$.

The adrenal glands were stained with Oil Red $\mathrm{O}$ as described (54).

Lipid chemistries. The levels of total sterols, free sterols and sterol esters were measured in adrenals as described (17). Briefly, mice were anesthetized 8 hours after the dark cycle and the adrenal glands were collected, dissected free of adipose tissue, rinsed in $0.9 \% \mathrm{NaCl}$, blotted dry, and then weighed. The adrenal glands were minced and the lipids were extracted in chloroform/methanol (2:1) in a glass tube. The levels of the free sterols were measured using gas chromatography. Total sterols were measured in parallel samples that were saponified prior to lipid extraction. Sterol esters were determined by subtracting the free sterols from the total sterols.

ACTH stimulation and the dexamethasone inhibition assay. The ACTH stimulation test was performed as described (17) in male mice (8-12 weeks old) with the following modifications. The mice were housed individually for one week prior to obtaining $200 \mu$ l of blood from the retro-orbital plexus for basal measurements of corticosterone. Plasma was isolated and stored at $-80^{\circ} \mathrm{C}$. Two weeks later, the mice were injected intraperitoneally with 0.5 $\mathrm{ml}$ of saline or with $50 \mu \mathrm{g}$ of ACTH in $0.5 \mathrm{ml}$ saline, as described (41). After 1 hour, blood samples were collected and plasma was isolated and frozen at $-80^{\circ} \mathrm{C}$. Corticosterone levels were measured in the laboratory of David Hess (Oregon Health Science University, Portland, Oregon, USA) (55).

For the dexamethasone inhibition assay, mice were injected intraperitoneally with either $0.2 \mathrm{ml}$ of saline or $160 \mu \mathrm{g}$ dexamethasone in $0.2 \mathrm{ml}$ of saline for 6 days. The mice were sacrificed 4 hours after the last injection. The adrenal glands were processed as described above, and the free sterols and sterol esters were quantified as previously described (17).

Quantitative real-time PCR. Total RNA was extracted from pooled adrenal glands using RNA Stat-60 kit (Tel-Test Inc.), and real-time PCR was performed as described $(56,57)$.

Preparation of adrenal homogenates and microsomes. The adrenal glands from $6 \mathrm{GSG}^{-1-}$ and 6 wild-type mice were stripped of fibrous and adipose tissue and homogenized in $1 \mathrm{ml}$ of TES buffer ( $20 \mathrm{mM}$ Tris-HCl, $1 \mathrm{mM}$ EDTA, and $250 \mathrm{mM}$ sucrose, $\mathrm{pH} 7.4$ ) using a polytron. The crude preparation was then centrifuged at $600 \mathrm{~g}$ for 10 minutes and the supernatant was collected (adrenal homogenate). The homogenate was centrifuged at $12,000 \mathrm{~g}$ for 15 
minutes and the supernatant was collected and recentrifuged at 100,000 $g$ for 30 minutes to obtain the microsomal pellet. The pellet was resuspended in a solution containing $50 \mathrm{mM}$ potassium phosphate and $2 \mathrm{mM}$ dithiothreitol ( $\mathrm{pH} 7.5)$, and then stored at $-80^{\circ} \mathrm{C}$.

Immunoblot analysis. Adrenal homogenates were prepared as described above and then centrifuged at $100,000 \mathrm{~g}$ for 30 minutes at $4{ }^{\circ} \mathrm{C}$. Membrane pellets were resuspended in SDS lysis buffer ( $1 \% \mathrm{SDS}, 100 \mathrm{mM} \mathrm{NaCl}, 1 \mathrm{mM}$ EDTA, 1 mM EGTA, and $10 \mathrm{mM}$ Tris- $\mathrm{HCl}, \mathrm{pH}$ 6.8) and size-fractionated on $8 \%$ SDS-polyacrylamide gels.

Y1-BS1 cells were lysed and membrane and nuclear fractions were prepared as previously described (58). Proteins were transferred to Hybond-C Extra Nitrocellulose filters (Catalog no. RPN303E, Amersham Biosciences), immunoblotted using antibodies to the LDLR, SR-BI, ABCA1, HMGCR, SREBP-2, and calnexin, incubated with HRP-conjugated goat anti-rabbit IgG (Sigma-Aldrich), and visualized using SuperSignal substrate system (Pierce Biotechnology Inc.).

ACAT, HSL, and HMGCR activity assays. The ACAT activity in the adrenal gland was determined as described (40), except that the cholesterol was added in $5 \%$ methyl- $\beta$-cyclodextrin rather than in acetone.

HSL was measured as described (59) except that an internal standard $\left(0.01 \mu \mathrm{Ci}\left[{ }^{3} \mathrm{H}\right]\right.$ oleic acid) was added when the reaction was terminated with addition of $3 \mathrm{ml}$ chloroform/methanol/heptane (250:230:180).

HMGCR activity in adrenals was measured as described (40).

Cholesterol synthesis assay. Y1-BS1 cell were set up at $0.5 \times 10^{6} \mathrm{cell} / \mathrm{dish}$ in $60 \mathrm{~mm}$ dishes on day 0 . On day 3 the cells were switched to medium containing NCLPPS ( $3 \mathrm{ml} /$ dish). After a 16 hour incubation, either 25-hydroxycholesterol ( $1 \mu \mathrm{g} / \mathrm{ml}$ 25-hydroxycholesterol, $10 \mu \mathrm{g} / \mathrm{ml}$ cholesterol) or stigmasterol $(50 \mu \mathrm{g} / \mathrm{ml})$ was added and the cells were incubated for an additional 24 hours. The incorporation of ${ }^{14} \mathrm{C}$ acetate into cholesterol was assayed as described (60).

Promoter reporter assay for LXR activity. CHO-7 cells were plated in 6-well plates on day 0 at a density of $2 \times 10^{5}$ cells per well. On day 1 , when the cells were $60 \%$ confluent, the cells were transfected with $0.26 \mu$ g of pCMXGal4-LXR- $\alpha$, an expression construct containing the LXR- $\alpha$ ligand binding site (amino acids 166-447) and $0.88 \mu \mathrm{g}$ pMH100X4-thymidine kinase-luc
(pMH100X4-TK-luc), a luciferase reporter construct $(61,62)$, and $0.5 \mu \mathrm{g}$ pCMX- $\beta$ Gal using Fugene 6 (Roche Applied Science) according to the manufacturer's protocol. Cells were then incubated in medium A containing $50 \mu \mathrm{M}$ contactin and $50 \mu \mathrm{M}$ melavonate supplemented with $5 \%$ NCLPPS. Sterols (in ethanol) and T0901317 (in DMSO) at the concentrations indicated in Figure 10 were added to the medium in the absence or presence of $200 \mu \mathrm{M}$ arachidonate. After $16 \mathrm{~h}$, the cells were harvested and the luciferase assay was performed as described (62).

Statistical analysis. All data are reported as the mean \pm the standard error of the mean (SEM). The differences between the mean values of $G 5 \mathrm{Gr}^{-/-}$ and of wild type mice were tested for statistical significance by the twotailed Student's $t$ test.

\section{Acknowledgments}

We thank especially Yinyan Ma and Amit Patel for excellent technical assistance. We also thank Jeffery Cormier and James Jennings for their assistance. We thank B. Schimmer and M. Ascoli for the kind gift of the Y1-BS-1 cells. We thank Klaus von Bergmann and Dieter Lutjohann for measurement of sterol levels in the adrenal glands of the ezetimibe-treated mice. We wish to thank David W. Russell for review of the manuscript. H.H. Hobbs is supported by the NIH (grants HL20948, HL72304, and HL20948), the Perot Family Fund, and the Donald W. Reynolds Clinical Cardiovascular Research Center in Dallas.

Received for publication May 18, 2004, and accepted in revised form July 27, 2004.

Address correspondence to: Helen H. Hobbs, Department of Molecular Genetics, University of Texas Southwestern Medical Center, 5323 Harry Hines Boulevard, Dallas, Texas 75390-9046, USA. Phone: (214) 648-6724; Fax: (214) 648-7539; E-mail: helen. hobbs@utsouthwestern.edu.

Chendong Yang and Liqing Yu contributed equally to this work.
1. Kuksis, A., Marai, L., Myher, J.J., and Geher, K. 1976. Identification of plant sterols in plasma and red blood cells of man and experimental animals. Lipids. 11:581-586.

2. Berge, K.E., et al. 2000. Accumulation of dietary cholesterol in sitosterolemia caused by mutations in adjacent $\mathrm{ABC}$ transporters. Science. 290:1771-1775.

3. Lee, M.H., et al. 2001. Identification of a gene, ABCG5, important in the regulation of dietary cholesterol absorption. Nat. Genet. 27:79-83.

4. Bhattacharyya, A.K., and Connor, W.E. 1974. Beta-sitosterolemia and xanthomatosis. A newly described lipid storage disease in two sisters. J. Clin. Invest. 53:1033-1043.

5. Salen, G., et al. 1989. Increased sitosterol absorption, decreased removal, and expanded body pools compensate for reduced cholesterol synthesis in sitosterolemia with xanthomatosis. J. Lipid Res. 30:1319-1330.

6. Yu, L., et al. 2002. Disruption of Abcg5 and Abcg8 in mice reveals their crucial role in biliary cholesterol secretion. Proc. Natl. Acad. Sci. U. S. A 99:16237-16242.

7. Yu, L., Von Bergmann, K., Lutjohann, D., Hobbs, H.H., and Cohen, J.C. 2004. Selective sterol accumulation in ABCG5/ABCG8-deficient mice. J. Lipid. Res. 45:301-307.

8. Gwynne, J.T., Mahaffee, D., Brewer, H.B., Jr., and Ney, R.L. 1976. Adrenal cholesterol uptake from plasma lipoprotein: regulation by corticotropin. Proc. Natl. Acad. Sci. U. S. A. 73:4329-4333.
9. Andersen, J.M., and Dietschy, J.M. 1978. Relative importance of high and low density lipoproteins in the regulation of cholesterol synthesis in the adrenal gland, ovary, and testis of the rat. J. Biol. Chem. 253:9024-9032.

10. Temel, R.E., et al. 1997. Scavenger receptor class $\mathrm{B}$, type I (SR-BI) is the major route for the delivery of high density lipoprotein cholesterol to the steroidogenic pathway in cultured mouse adrenocortical cells. Proc. Natl. Acad. Sci. U. S. A. 94:13600-13605.

11. Brown, M.S., Kovanen, P.T., and Goldstein, J.L. 1979. Receptor-mediated uptake of lipoporteincholesterol and its utilization for steroid synthesis in the adrenal cortex. Recent Prog. Horm. Res. 35:215-257.

12. Kovanen, P.T., Schneider, W.J., Hillman, G.M., Goldstein, J.L., and Brown, M.S. 1979. Separate mechanisms for the uptake of high and low density lipoproteins by mouse adrenal gland in vivo. J. Biol. Chem. 254:5498-5505.

13. Carr, B.R., Porter, J.C., MacDonald, P.C., and Simpson, E.R. 1980. Metabolism of low density lipoprotein by human fetal adrenal tissue. Endocrinology. 107:1034-1040

14. Kovanen, P.T., Goldstein, J.L., Chappell, D.A., and Brown, M.S. 1980. Regulation of low density lipoprotein receptors by adrenocorticotropin in the adrenal gland of mice and rats in vivo. J. Biol. Chem. 255:5591-5598.

15. Rigotti, A., et al. 1996. Regulation by adrenocortico- tropic hormone of the in vivo expression of scavenger receptor class B type I (SR-BI), a high density lipoprotein receptor, in steroidogenic cells of the murine adrenal gland. J. Biol. Chem. 271:33545-33549.

16. Cao, G., et al. 1999. Developmental and hormonal regulation of murine scavenger receptor, class B, type 1. Mol. Endocrinol. 13:1460-1473.

17. Plump, A.S., et al. 1996. Apolipoprotein A-I is required for cholesteryl ester accumulation in steroidogenic cells and for normal adrenal steroid production. J. Clin. Invest. 97:2660-2671.

18. $\mathrm{Ng}$, D.S., et al. 1997. Disruption of the murine lecithin:cholesterol acyltransferase gene causes impairment of adrenal lipid delivery and up-regulation of scavenger receptor class B type I. J. Biol. Chem. 272:15777-15781.

19. Rigotti, A., et al. 1997. A targeted mutation in the murine gene encoding the high density lipoprotein (HDL) receptor scavenger receptor class B type I reveals its key role in HDL metabolism. Proc. Natl. Acad. Sci. U. S. A. 94:12610-12615.

20. Gwynne, J.T., and Strauss, J.F., III. 1982. The role of lipoproteins in steroidogenesis and cholesterol metabolism in steroidogenic glands. Endocr. Rev. 3:299-329.

21. Meiner, V.L., et al. 1996. Disruption of the acyl-CoA: cholesterol acyltransferase gene in mice: evidence suggesting multiple cholesterol esterification enzymes in mammals. Proc. Natl. Acad. Sci. U. S. A. 93:14041-14046.

22. Costet, P., Luo, Y., Wang, N., and Tall, A.R. 2000. 
Sterol-dependent transactivation of the $\mathrm{ABC} 1$ promoter by the liver $\mathrm{X}$ receptor/retinoid $\mathrm{X}$ receptor. J. Biol. Chem. 275:28240-28245.

23. Repa, J.J., et al. 2000. Regulation of mouse sterol regulatory element-binding protein-1c gene (SREBP-1c) by oxysterol receptors, $\operatorname{LXR} \alpha$ and LXR $\beta$. Genes Dev. 14:2819-2830.

24. Joseph, S.B., et al. 2002. Direct and indirect mechanisms for regulation of fatty acid synthase gene expression by liver X receptors. J. Biol. Chem. 277:11019-11025.

25. Sun, Y., et al. 2003. Stearoyl-CoA desaturase inhibits ATP-binding cassette transporter A1-mediated cholesterol efflux and modulates membrane domain structure. J. Biol. Chem. 278:5813-5820.

26. Van Heek, M., et al. 1997. In vivo metabolismbased discovery of a potent cholesterol absorption inhibitor, SCH58235, in the rat and rhesus monkey through the identification of the active metabolites of SCH48461. J. Pharmacol. Exp. Ther 283:157-163.

27. Horton, J.D., Goldstein, J.L., and Brown, M. 2002. SREBPs: activators of the complete program of cholesterol and fatty acid synthesis in the liver. J. Clin. Invest. 109:1125-1131. doi:10.1172/ JCI200215593.

28. Ou, J., et al. 2001. Unsaturated fatty acids inhibit transcription of the sterol regulatory elementbinding protein-1c (SREBP-1c) gene by antagonizing ligand-dependent activation of the LXR. Proc Natl. Acad. Sci. U. S. A. 98:6027-6032.

29. Reaven, E., et al. 1998. Expression and microvillar localization of scavenger receptor, class B, type (a high density lipoprotein receptor) in luteinized and hormone-desensitized rat ovarian models. Endocrinology. 139:2847-2856.

30. Field, F.J., Born, E., and Mathur, S.N. 2004. LXR/ RXR ligand activation enhances the basolatera efflux of beta -sitosterol in CaCo-2 cells. J. Lipid Res. 45:905-914.

31. Schwartz, K., Lawn, R.M., and Wade, D.P. 2000. ABC1 gene expression and ApoA-I-mediated cholesterol efflux are regulated by LXR. Biochem. Biophys. Res. Commun. 274:794-802.

32. Repa, J.J., et al. 2000. Regulation of absorption and ABC1-mediated efflux of cholesterol by RXR heterodimers. Science. 289:1524-1529.

33. Kaneko, E., et al. 2003. Induction of intestinal ATPbinding cassette transporters by a phytosterolderived liver X receptor agonist. J. Biol. Chem. 278:36091-36098.

34. Lawn, R.M., et al. 1999. The Tangier disease gene product $\mathrm{ABC} 1$ controls the cellular apolipoprotein mediated lipid removal pathway. J. Clin. Invest. 104:25-31.

35. Gan, X., et al. 2001. Dual mechanisms of ABCA1 regulation by geranylgeranyl pyrophosphate. J. Biol. Chem. 276:48702-48708.

36. Arakawa, R., and Yokoyama, S. 2002. Helical apolipoproteins stabilize ATP-binding cassette transporter $\mathrm{A} 1$ by protecting it from thiol protease-medi- ated degradation. J. Biol. Chem. 277:22426-22429.

37. Martinez, L.O., Agerholm-Larsen, B., Wang, N., Chen, W., and Tall, A.R. 2003. Phosphorylation of a Pest sequence in ABCA1 promotes calpain degradation and is reversed by ApoA-I. J. Biol. Chem. 278:37368-37374.

38. Wang, Y., and Oram, J.F. 2002. Unsaturated fatty acids inhibit cholesterol efflux from macrophages by increasing degradation of ATP-binding cassette transporter A1. J. Biol. Chem. 277:5692-5697.

39. Wang, N., Weng, W., Breslow, J.L., and Tall, A.R. 1996. Scavenger receptor BI (SR-BI) is up-regulated in adrenal gland in apolipoprotein A-I and hepatic lipase knock-out mice as a response to depletion of cholesterol stores. In vivo evidence that SR-BI is a functional high density lipoprotein receptor under feedback control. J. Biol. Chem. 271:21001-21004.

40. Balasubramaniam, S., Goldstein, J.L., Faust, J.R , Brunschede, G.Y., and Brown, M.S. 1977. Lipoprotein-mediated regulation of 3-hydroxy-3 methylglutaryl coenzyme A reductase activity and cholesteryl ester metabolism in the adrenal gland of the rat. J. Biol. Chem. 252:1771-1779.

41. Sun, Y., Wang, N., and Tall, A.R. 1999. Regulation of adrenal scavenger receptor-BI expression by ACTH and cellular cholesterol pools. J. Lipid Res. 40:1799-1805.

42. Field, F.J., Born, E., and Mathur, S.N. 1997. Effect of micellar beta-sitosterol on cholesterol metabolism in CaCo-2 cells. J. Lipid Res. 38:348-360.

43. Brown, M.S., and Goldstein, J.L. 1974. Suppression of 3-hydroxy-3-methylglutaryl coenzyme A reductase activity and inhibition of growth of human fibroblasts by 7-ketocholesterol. J. Biol. Chem. 249:7306-7314.

44. Brown, M.S., and Goldstein, J.L. 1997. The SREBP pathway: regulation of cholesterol metabolism by proteolysis of a membrane-bound transcription factor. Cell. 89:331-340.

45. Aringer, L., Eneroth, P., and Nordstrom, L. 1979. Side-chain cleavage of 4-cholesten-3-one, 5-cholesten-3a-ol, b-sitosterol, and related steroids in endocrine tissues from rat and man. J. Steroid Biochem. 11:1271-1285.

46. Arthur, J.R., Blair, H.A.F., Boyd, G.S., Mason, J.I., and Suckling, K.E. 1976. Oxidation of cholesterol and cholesterol analogues by mitochondrial preparations of steroid-hormone-producing tissue. Biochem. J. 158:47-51.

47. Morisaki, M., Duque, C., Ikekawa, N., and Shikita, M. 1980. Substrate specificity of adrenocortical cytochrome P-450scc--I. Effect of structural modification of cholesterol side-chain on pregnenolone production. J. Steroid Biochem. 13:545-550.

48. Salen, G., et al. 1985. Lethal atherosclerosis associated with abnormal plasma and tissue sterol composition in sitosterolemia with xanthomatosis. J. Lipid Res. 26:1126-1133.

49. Herz, J., Kowal, R.C., Ho, Y.K., Brown, M.S., and Goldstein, J.L. 1990. Low density lipoprotein receptor-related protein mediates endocytosis of mono- clonal antibodies in cultured cells and rabbit liver. J. Biol. Chem. 265:21355-21362.

50. Landschulz, K.T., Pathak, R.K., Rigotti, A., Krieger, M., and Hobbs, H.H. 1996. Regulation of scavenger receptor, class B, type I, a high density lipoprotein receptor, in liver and steroidogenic tissues of the rat. J. Clin. Invest. 98:984-995.

51. Shimano, H., et al. 1997. Elevated levels of SREBP-2 and cholesterol synthesis in livers of mice homozygous for a targeted disruption of the SREBP-1 gene. J. Clin. Invest. 100:2115-2124.

52. Liscum, L., et al. 1983. Regulation of 3-hydroxy3-methylglutaryl Coenzyme A reductase and its mRNA in rat liver as studied with a monoclonal antibody and a cDNA probe. J. Biol. Chem. 258:8450-8455.

53. Fitzgerald, M.L., et al. 2001. ATP-binding cassette transporter A1 contains an NH2-terminal signal anchor sequence that translocates the protein's first hydrophilic domain to the exoplasmic space. J. Biol. Chem. 276:15137-15145.

54. Sheehan, D.C., and Hrapchak, B.B. 1980. Theory and practice of histotechnology. 2nd Edition. Mosby. St. Louis, Missouri, USA. 481 pp.

55. Gruenewald, D.A., Hess, D.L., Wilkinson, C.W., and Matsumoto, A.M. 1992. Excessive testicular progesterone secretion in aged male Fischer 344 rats: a potential cause of age-related gonadotropin suppression and confounding variable in aging studies. J. Gerontol. 47:B164-B170.

56. Liang, G., et al. 2002. Diminished hepatic response to fasting/refeeding and LXR agonists in mice with selective deficiency of SREBP-1c. J. Biol. Chem. 277:9520-9528

57. Yang, J., et al. 2001. Decreased lipid synthesis in livers of mice with disrupted Site-1 protease gene. Proc. Natl. Acad. Sci. U. S. A. 98:13607-13612.

58. Sever, N., Yang, T., Brown, M.S., Goldstein, J.L., and DeBose-Boyd, R.A. 2003. Accelerated degradation of HMG CoA reductase mediated by binding of insig-1 to its sterol-sensing domain. Mol. Cell. 11:25-33.

59. Kraemer, F.B., et al. 2002. Adrenal neutral cholesteryl ester hydrolase: identification, subcellular distribution, and sex differences. Endocrinology. 143:801-806.

60. Ho, Y.K., Faust, J.R., Bilheimer, D.W., Brown, M.S. and Goldstein, J.L. 1977. Regulation of cholesterol synthesis by low density lipoprotein in isolated human lymphocytes. J. Exp. Med. 145:1531-1549.

61. Willy, P.J., et al. 1995. LXR, a nuclear receptor that defines a distinct retinoid response pathway. Genes Dev. 9:1033-1045.

62. Cheng, J.B., Motola, D.L., Mangelsdorf, D.J., and Russell, D.W. 2003. De-orphanization of cytochrome P450 2R1: a microsomal vitamin D 25-hydroxylase. J. Biol. Chem. 278:38084-38093.

63. Berge, K.E., et al. 2002. Heritability of plasma noncholesterol sterols and relationship to DNA sequence polymorphism in ABCG5 and ABCG8. J. Lipid Res. 43:486-494 